\title{
Increasing Storage Battery Lifetime in Autonomous Photovoltaic Systems with Power Generation Structure Varying Throughout the Year
}

\author{
Dmitriy N. Karamov ${ }^{1 *}$, Ildar R. Muftahov ${ }^{12}$ and Alexey V. Zhukov ${ }^{1}$ \\ ${ }^{1}$ Melentiev Energy Systems Institute, 130 Lermontov str., Irkutsk, Russia \\ ${ }^{2}$ Main Computing Center, Russian Railways, 25A Mayakovskogo str., Irkutsk, Russia
}

\begin{abstract}
This paper substantiates the use of photovoltaic systems with power generation structure varying throughout the year. This research topic emerged from an in-depth analysis of the operating modes of autonomous photovoltaic systems located in Siberia and the Russian Far East. The paper gives a detailed and concise description of a methodology for modelling such a system with account of issues relating to the operational sustainability of diesel and solar power stations in autumn and winter. In spring and summer, autonomous photovoltaic systems operate using the standard power accumulation algorithm whereas the diesel power station serves as a stand-by power source thereby increasing the lifetime of storage batteries, reducing the number of their replacements and cutting down costs through discounting. The overall levelized cost of energy drops off significantly too. The paper presents the results of modelling an actual autonomous energy system in which a solar power station equipped with storage batteries is planned to be constructed in the near future. The modelling results revealed that using a structure varying throughout the year increases storage battery lifetime from 6 to 11 years, and there is only one (instead of three) replacement throughout the life of the batteries. The obtained results have been taken into consideration and are to be put into practice in setting up the photovoltaic system under review. The presented approach is versatile and can be used to analyze various photovoltaic systems.
\end{abstract}

\section{Introduction}

Deep integration of renewable sources of energy and energy accumulation systems defines the current appearance of energy systems [1]. The latter's transformation is accompanied by the acquisition of new properties and specificities stemming from various energy generation sources and systems of energy transformation, transmission, regulation and accumulation. Importantly, this transformation has affected virtually all voltage levels of energy systems, including major photovoltaic systems and wind farms, elements of medium-voltage power distribution and small-sized, privately-owned integrated energy systems, installed at consumers' homes [2].

Renewable sources of energy have also become indispensable in developing remote rural areas. The integration of renewables and energy storage batteries into such systems considerably improves quality of life, cuts costs by reducing organic fuel consumption, improves the environmental record and so on $[3,4]$.

\subsection{Equipment optimization problem}

The main challenge associated with the use of renewable sources of energy is the optimization of equipment composition and installed power capacity [5]. Various criteria for evaluating the efficiency of renewable energy use can act as the target function. As an example, the target function is usually represented by the levelized cost of energy $(\$ / \mathrm{kW} \cdot \mathrm{h})$ in autonomous energy systems; by the maximized number of hours of autonomous power supply and the minimized value of lost load, in stand-by and emergency power supply systems; and by the amount of saved organic fuel and investors' returns, in power generation facilities under energy service contract [6]. The above criteria can be combined and expanded depending on the modalities of the problem.

\section{Background of the present research study}

This section presents the sequence of events that led to the setting of this problem. It results from an in-depth analysis of the operational modes of existing autonomous photovoltaic systems with power storage batteries, located in Siberia and the Russian Far East.

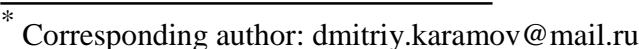




\subsection{Analysis of the operational modes of existing photovoltaic systems}

Over the past four years, the authors have gathered information on the operational modes of autonomous photovoltaic systems in Siberia and the Far East. Considerable time was devoted to communication with organizations in charge of the maintenance of these systems. Also, the authors prepared a questionnaire for service personnel with a view to detecting specific patterns in operating such systems. The available data was used to draw up a list of tasks that are part of this research.

\subsubsection{Low density of power generation in photovoltaic systems in autumn and winter}

Many autonomous photovoltaic systems are situated in the central and northern areas of Siberia and the Russian Far East in which solar irradiance is subject to considerable fluctuation throughout the year. Also, some autonomous systems are located in relatively close proximity to the polar circle where astronomical phenomena such as polar day and polar night are observed. In wintertime, the power generation of photovoltaic systems does not attain even $10 \%$ of the capacity of operating diesel power stations.

\subsubsection{High values of residential electricity load}

In autumn and winter, residential electricity load values are highest throughout the year. In some autonomous systems, electricity load is 2.5 to 3 times higher in autumn and winter, compared to summer, which is mostly due to extremely cold temperatures (ranging from $-35^{\circ} \mathrm{C}$ to $-50^{\circ} \mathrm{C}$ ) during these periods.

\subsubsection{High utilization rate of power storage batteries}

Many power generating companies point out that, in autumn and winter, storage batteries are not recommended for use in photovoltaic systems located in Siberia and the Russian Far East. For instance, the storage batteries of several autonomous photovoltaic systems failed due to a low state of charge of storage batteries characterized by a decrease in electrolyte density. As a result, the batteries covered with a thick layer of ice went out of order. Detailed information is also available on the use of lithium-ion batteries requiring a constantly positive ambient temperature in the storage battery room. Such restrictions make it exceedingly difficult to operate lithium-ion storage batteries in Siberia and the Russian Far East.

The authors also tested the technical condition of storage batteries in three autonomous photovoltaic systems similar in terms of capacity and composition of equipment. The results revealed that, after two years of operation, the residual life of storage batteries varies between $60 \%$ and $70 \%$. At this rate, the storage batteries will be out of service in 2.5 to 3 years, which is an extremely short life. According to the authors, this fact is related to severe operating conditions in wintertime, often accompanied by frequent deep discharges.

Considering a substantial share of storage batteries in total investment (between 40\% and 50\%), their operational life is extremely short.

\subsection{Verbal description of research}

After analyzing the operating modes of many autonomous photovoltaic systems and detecting a number of patterns specific to the conditions of Siberia and the Russian Far East, the authors suggested using a photovoltaic system structure varying over the course of the year. This would allow a photovoltaic system to operate, in autumn and winter, in parallel with a diesel power station and without accumulating power. At this time storage batteries are disconnected from the photovoltaic system and fully charged.

From spring onwards when the photovoltaic system's power generation increases sharply, storage batteries are again operated in cyclic mode and the diesel power station is used as a stand-by power source.

This paper aims to present a technical solution to the variable structure of photovoltaic systems throughout the year. Besides, the authors describe the model of such a photovoltaic system with account of storage battery lifetime, providing an estimate of how the variable power generation structure will affect storage battery lifetime.

\section{Description of the methodology}

This section describes the methodological approach consisting of three main parts. Part 1 focuses on the generation of climatic indicators required to model a photovoltaic system's modes. Part 2 presents the structure and operational modes of a photovoltaic system. Part 3 calculates storage battery lifetime depending on equipment composition, operational modes, depth of discharge and other indicators.

\subsection{Climate information}

To increase the accuracy of study findings, the above parameters should approximate as much as possible the actual values observed in the area under investigation. To this end, the authors use a methodology based on data from publicly available multi-year meteorological data seta in which main climatic parameters are recorded line by line with a discrete step size. The latter depends on the type of weather station and the international meteorological format. FM 12 Synop and METeorological Aerodrome Report (METAR) are the most widespread meteorological formats. The former is intended for the instantaneous presentation of observational data coming from land weather stations, including coast-based ones. METAR is used to transmit reports on current weather conditions at airports. In both formats data is recorded in a strictly specified manner. Multi-year meteorological data sets are well-ordered and detailed information. Analysis of such data enables a 
realistic description of changes in the natural and climatic indicators in a given area.

This approach has worked well in solving various systemic energy problems.

\subsubsection{Solar radiation}

Solar radiation affecting the Earth's surface is inconstant and depends on two sets of invariable and variable parameters. The first set includes geographical coordinates, hour zone, the number of days of the calculation period, day duration and sunrise, zenith and sunset time. The second set of parameters comprises cloud cover and composition, cloud albedo, the Earth's surface albedo, atmospheric mass with account of changing pressure, air temperature, changes in the thickness of the ozone layer and in the spectral content of the visible light region and presence of water vapor and aerosols in clouds.

In calculating solar radiation for each day, sunrise, zenith and sunset time is defined based on the geographical coordinates and time zone of a given area. Time intervals in which the Sun's local hour angle is above zero are identified first. Then direct, diffuse and global solar radiation are calculated taking account of actual cloud cover in the area under review.

The calculations involve two mathematical models, Iqbal and Kasten-Czeplak. In the first stage, the Iqbal model is used to calculate clear sky radiation. The second stage applies the Kasten-Czeplak model to specify the attenuation coefficient of solar radiation based on cloud cover, cloud composition and the percentage of bad weather clouds. A detailed mathematical description and algorithms for calculating solar radiation using multi-year meteorological data sets for various natural and climatic zones are found in [7].

\subsubsection{Generation of a typical meteorological year}

A typical meteorological year is a selection of meteorological data for every hour in a year and for a specific geographical location. Multi-year meteorological data sets spanning eight or more years are used to generate data values. The expert-based selection of weather parameters depends on the nature of the problem being solved. In systemic energy research, weather data are selected with relation to the level of detail of mathematical models for power generating elements.

These models set requirements on the source array data which, if satisfied, contribute to a more accurate estimation of the mode indicator values [8].

\subsection{Model of an autonomous photovoltaic system with a variable structure}

Autonomous photovoltaic systems consist of solar arrays (PV), solar inverters (INV_s), diesel generators (DG), battery inverters (INV_b), storage batteries (SB) and a control system.

Figure $1(\mathrm{a}, \mathrm{b})$ shows a graphic representation of a photovoltaic system with a variable structure. (a - Autumn - Winter)
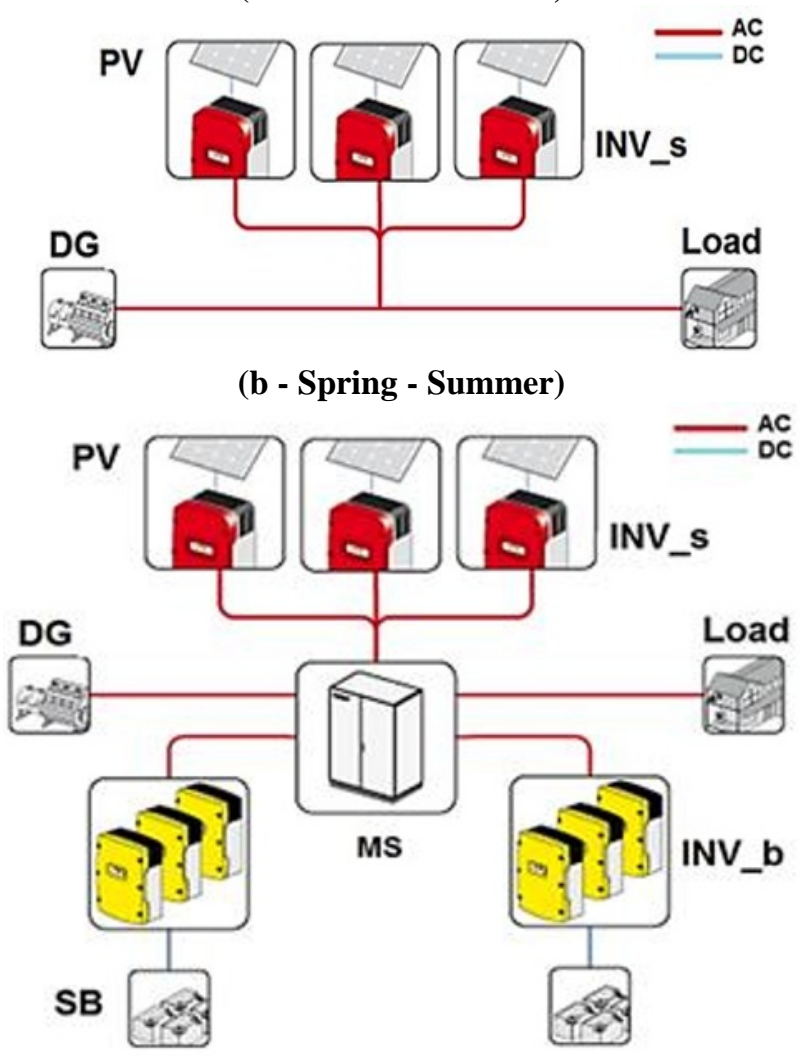

Fig. 1. Graphic representation of a photovoltaic system with a variable structure (www.sma.de).

The model should take into account control algorithms in terms of the photovoltaic system's equipment composition and structure.

\section{Autumn - Winter}

An autonomous photovoltaic system model consists of a diesel power station (the leader) operating together with a solar power station (the led). Operational constraints are generated accordingly and reflected in the load factor of the operating diesel generators which should not be below $30 \%$. Automatically controlled network inverters ensure respect of these constraints as well as a normal and safe functioning of the entire autonomous photovoltaic system.

1. If the solar station produces enough power to provide electricity directly to consumers, the electrical load (up to $70 \%$ ) is covered at its expense.

2. If the power generated by the solar station exceeds the admissible flow limit, the network inverter regulates it in view of the constraints.

3. Only the diesel power station supplies electricity at nighttime.

The mode of operation of diesel generators is modelled using the diesel engine's universal velocity characteristic. This approach defines all the required operating conditions such as shaft load, power output, revolutions per minute, fuel consumption rate and running hours. A detailed description of this approach is given in the following paper [9].

Papers $[6,9]$ provide calculations of the solar station's operating parameters such as power output, output 
current, voltage, changes in solar panels' efficiency depending on climatic parameters, changes in the temperature of solar panels and so on.

\section{Spring - Summer}

The system's known parameters are active power values in its subsystems, i.e. scalar argument functions $t$. Consequently, the value of the power function is as follows:

$$
\begin{aligned}
& P_{S}(t)=P_{P V}(t)+P_{D G}(t)-P_{L}(t)-\Delta P_{\Sigma}(t) \\
& \Delta P_{\Sigma}(t)=\Delta P_{\text {Line }}(t)+\Delta P_{I N V}(t)+\Delta P_{D C B}(t)
\end{aligned}
$$

where $P_{P V}(t)$ is active power generation in the photovoltaic system, $\mathrm{kW} ; P_{D G}(t)$ is active power generation in the diesel generator, $\mathrm{kW}$; and $P_{L}(t)$ is electrical load, $\mathrm{kW} ; \Delta P_{\text {Line }}(t)$ are power losses in cable and overhead lines, $\mathrm{kW}$; and $\Delta P_{I N V}(t), \Delta P_{D C B}(t)$ are active power losses in the solar inverters or DC combiner boxes, $\mathrm{kW}$.

Three mutually exclusive states can represent the alternating power function $P_{S}(t), P_{S}(t)^{+}, P_{S}(t)^{-}, P_{S}(t)^{0}$ The actual operating mode of an energy system is determined on the basis of the alternating power function $P_{S}(t)$.

The following is the verbal and mathematical description of the control algorithm.

- If power generation from renewable energy sources is superior to the current power load value $P_{P V}(t)-\Delta P_{\Sigma}(t) \geq P_{L}(t)$ electricity is supplied to consumers and surplus energy goes to the storage battery:

$$
P_{S}(t)^{+}=\left\{\begin{array}{c}
P_{S}(t) ; P_{S}(t)>0 \& \bar{a}_{S B} \geq \bar{b}_{S B}(t) \cdot P_{S}(t) \\
\bar{a}_{S B} ; P_{S}(t)>0 \& \bar{a}_{S B}<\bar{b}_{S B}(t) \cdot P_{S}(t) \\
0 ; P_{S}(t)<0
\end{array}\right\},
$$

where $\bar{a}_{S B}$ is a system of limitations for the amount of storage battery charge and discharge based on technical specifications and defined as follows:

$$
\bar{a}_{S B}=\left(Q_{S B}^{\max }-Q_{S B}^{\text {min }}\right) \cdot \bar{k}_{S B},
$$

where $Q_{S B}^{\max }$ is the installed storage battery capacity, $\mathrm{kW} \cdot \mathrm{h} ; Q_{S B}^{\min }$ is the minimum permissible state of charge of storage batteries under which a standby electric source turns on usually ranging between $20 \%$ and $30 \%$ of $Q_{S B}^{\max }$, $\mathrm{kW} \cdot \mathrm{h} ; \bar{k}_{S B}$ is the charge/discharge coefficient of storage batteries (ranging between $10 \%$ and $40 \%$ of $Q_{S B}^{\max }$ for different types of batteries), $\mathrm{kW} \cdot \mathrm{h}$.

The following system of logical conditions is also devised for the power conversion and accumulation link $\bar{b}_{S B}$ :

$$
\bar{b}_{S B}(t)=\left\{\eta_{S B}(t) \cdot \eta_{B I N}\right\},
$$

where $\eta_{S B}(t), \eta_{B I N}$ is storage battery and battery inverter efficiency, $\%$.

- If power generation from renewable energy sources is inferior to the current power load value $P_{P V}(t)-\Delta P_{\Sigma}(t) \leq P_{L}(t)$ the power generated by the solar plant is supplied to consumers and the lacking power comes from the storage battery:

$$
P_{S}(t)^{-}=\left\{\begin{array}{c}
P_{S}(t) ; P_{S}(t)<0 \& \bar{a}_{S B} \geq \frac{P_{S}(t)}{\bar{b}_{S B}(t)} \\
\frac{\bar{a}_{S B}}{\bar{b}_{S B}(t)} \cdot \Delta t ; P_{S}(t)<0 \& \bar{a}_{S B}<\frac{P_{S}(t)}{\bar{b}_{S B}(t)} \\
0 ; P_{S}(t)>0
\end{array}\right\} .
$$

- $\quad$ Consumers are supplied with electricity coming directly from the solar plant when storage batteries are fully charged $(100 \%)$ :

$$
P_{S}(t)^{0}=\left\{\begin{array}{c}
P_{L}(t) ; P_{S}(t)>P_{L}(t) \& Q_{S B}(t)=Q_{S B}^{\max } \\
0 ; Q_{S B}(t)<100
\end{array}\right\} .
$$

- If power generation from renewable energy sources is inferior to the current power load value and the storage battery's state of charge is inferior to a specific threshold value ( $20 \%$ to $30 \%$ of $)$, a standby power source, i.e. a diesel generator, turns on.

\subsubsection{Modelling storage battery lifetime}

This study calculates storage battery lifetime by modelling partial charge/discharge cycle and defining the limit number of cycles to failure depending on depth of discharge and Cycle Life vs Depth of Discharge. The average annual number of charge/discharge cycles is also calculated in terms of the overall installed storage battery capacity and operational constraints.

Consideration given to the local minimum of the state of charge of battery for each charge/discharge cycle defines the model's scientific novelty. Finding the average annual value of the local minimum of the state of charge and comparing it to the Cycle Life vs. Depth of Discharge characteristic makes it possible to define the number of cycles to failure. At a later stage, it is possible to calculate discounted battery replacement costs.

The author's paper [10] gives a comprehensive description of the approach under review and its practical application.

\section{Target of the study and numerical results}

An autonomous energy system located in Eastern Siberia was chosen as the target of the present study. The system's name and geographical location are not disclosed at the request of the companies implementing this project. That said, its technical specifications, formally approved by all parties, can be presented in this paper.

Currently this autonomous system is equipped with two $70 \mathrm{~kW}$ and $50 \mathrm{~kW}$ diesel generators. The maximum electrical load of $52 \mathrm{~kW}$ is observed in winter whereas, in summertime, the electrical load does not exceed $27 \mathrm{~kW}$. The annual diesel fuel consumption totals 54 tons. The levelized cost of energy (for diesel power generation only) is $32.09 \mathrm{RUB} / \mathrm{kW} \cdot \mathrm{h}$. 
A photovoltaic system is planned to be set up in this locality shortly. The approved set of equipment is as follows: one $50 \mathrm{~kW}$ solar power station; $3 \mathrm{~kW}$ to $20 \mathrm{~kW}$ solar inverters (for a total of $60 \mathrm{~kW}$ ); $192 \mathrm{~kW} \cdot \mathrm{h}$ OPzS storage batteries; and two $30 \mathrm{~kW}$ battery inverters (for a total of $60 \mathrm{~kW})$.

\subsection{Operation of photovoltaic systems with an invariable structure}

If the photovoltaic system under discussion operates following the classic pattern when the diesel station serves as a stand-by power source, the annual power generation values will be as follows: direct power supply, thous. $\mathrm{kW} \cdot \mathrm{h}$ : DG 44.61 and PV: 46.77; battery charging, thous. $\mathrm{kW} \cdot \mathrm{h}$ - DG: 63.61 and PV: 11.26; total generation, thous. $\mathrm{kW} \cdot \mathrm{h}$ - DG: 108.22 and PV: 58.03; total power supplied to consumers, thous. $\mathrm{kW} \cdot \mathrm{h}-166.25$. The annual diesel fuel consumption amounts to 23.2 tons.

Figure 2 shows the photovoltaic system's operating modes.
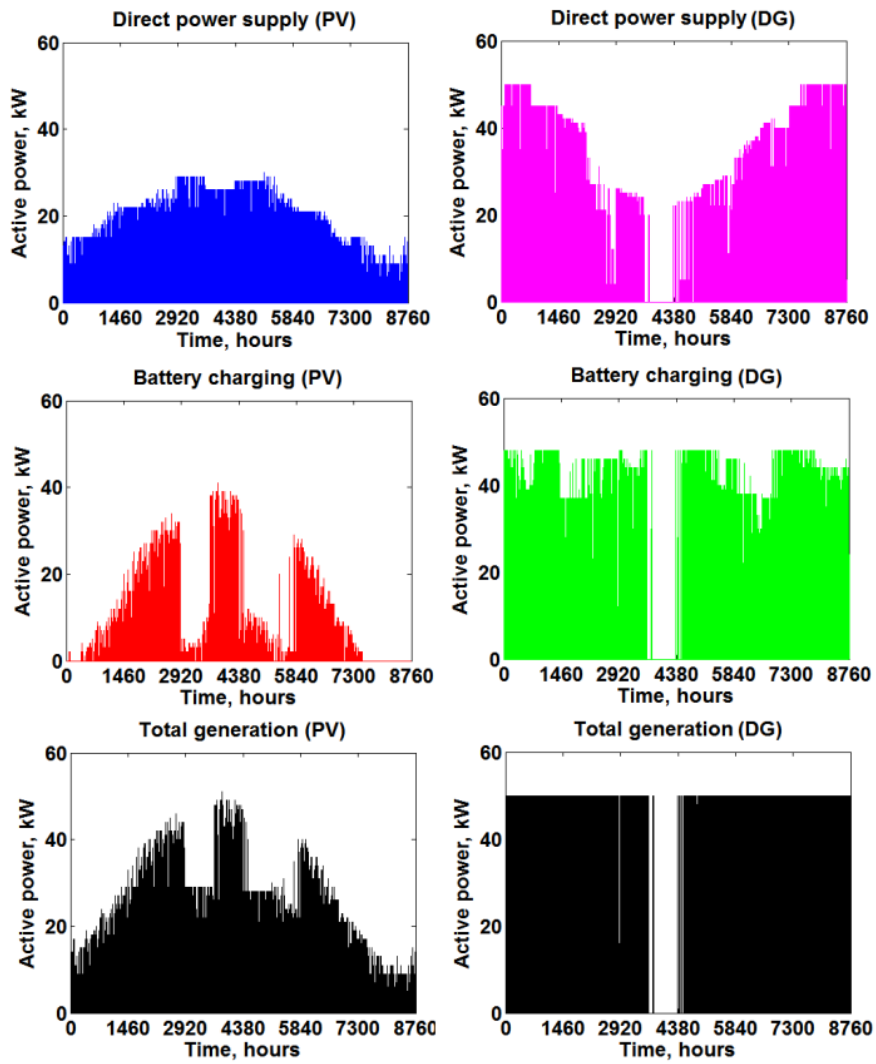

Figure 2. Operating modes of the photovoltaic system with an invariable structure.

Under such operating modes (with account of depth of discharge), the maximum number of charge/discharge cycles of storage batteries is 2075 , and the average value of charge/discharge cycles is 390 or 1.07 per day. Given these modes, the expected lifetime of storage batteries of such total capacity is 6 years. Therefore, three battery replacements will be needed throughout the life of the batteries (20 years). The total cost of three discounted battery replacements is 9.39 million rubles.
The total levelized cost of energy including battery replacement costs is $19.50 \mathrm{RUB} / \mathrm{kW} \cdot \mathrm{h}$.

\subsection{Operation of photovoltaic systems with a variable structure}

If the operating photovoltaic system has a variable structure, the annual power generation values will be as follows: direct power supply, thous. $\mathrm{kW} \cdot \mathrm{h}$ : DG 77.07 and PV: 46.77; battery charging, thous. $\mathrm{kW} \cdot \mathrm{h}-\mathrm{DG}: 31.60$ and PV: 10.80 ; total generation, thous. $\mathrm{kW} \cdot \mathrm{h}-\mathrm{DG}: 108.68$ and PV: 57.57; total power supplied to consumers, thous. $\mathrm{kW} \cdot \mathrm{h}-166.25$. The annual diesel fuel consumption amounts to 24.6 tons.

Figure 3 shows the operating modes of the photovoltaic system with a variable structure.
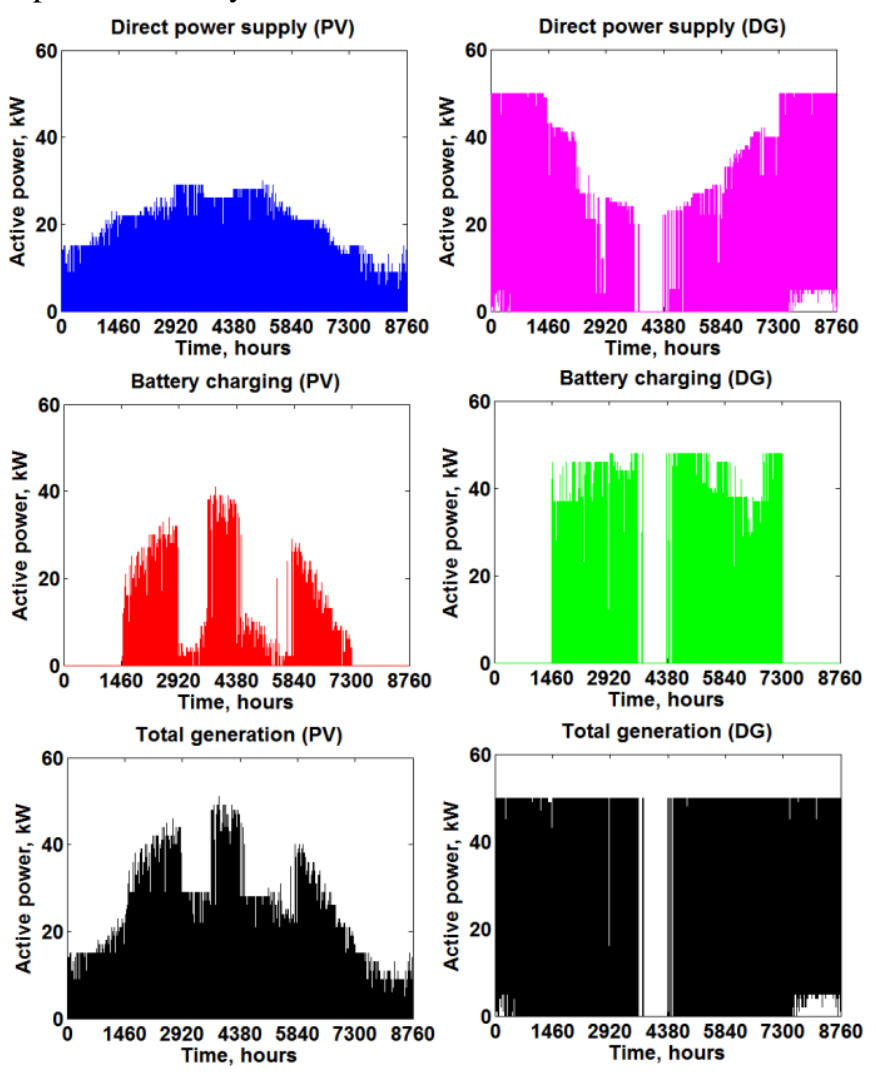

Figure 3. Operating modes of the photovoltaic system with a variable structure.

As shown in Figure 3, storage batteries are disconnected from the photovoltaic system and inoperative in winter and, partially, in autumn.

Excluding storage batteries from equipment composition in winter and autumn increases the maximum number of charge/discharge cycles. As an example, the maximum number of charge/discharge cycles is 2275, and the average annual number of charge/discharge cycles is 221 . Under these conditions, the expected lifetime of storage batteries is 11 years, batteries are to be replaced once and the discounted cost of such a replacement is 3.29 million rubles.

The final levelized cost of energy including one battery replacement is $17.66 \mathrm{RUB} / \mathrm{kW} \cdot \mathrm{h}$. 


\section{Conclusion}

This paper describes the operation of autonomous photovoltaic systems having a variable structure aimed mostly at reducing the negative impact on storage batteries in autumn and winter when the density of the photovoltaic system's power generation is lowest.

To meet this objective, the present study proposes a methodology for modelling such a system with account of variable operation algorithms and operational sustainability in winter and autumn. In spring and summer, this system operates in parallel with storage batteries and the diesel station serves as a stand-by power source.

The study also presents the results of modelling an actual autonomous energy system in which a solar power station equipped with storage batteries is planned to be constructed in the near future.

The obtained numerical results point to the following conclusions:

1. The variable structure of the autonomous photovoltaic system considerably increases storage battery lifetime, as reflected by the withdrawal of storage batteries from the photovoltaic system's equipment composition in autumn and winter.

2. There is a slight increase in the annual diesel fuel consumption resulting in costs related to overconsumption of diesel fuel. This is due to the fact that in autumn and winter the diesel and solar power stations are the leader and the led, respectively. The cumulative effect, however, almost doubles the lifetime of storage batteries.

3. The maximum number of cycles to failure increases, which is attributable primarily to storage batteries' use in favorable operating modes.

4. The number of storage battery replacements decreases throughout the entire lifetime of batteries, resulting in a reduction of costs.

5. The levelized cost of energy decreases significantly.

The presented approach and methodology are versatile and can be used in different autonomous photovoltaic systems.

The research was carried out under RFBR and the Government of the Irkutsk Region, project number 20-48383004.

\section{Practical application}

This methodology was used in the implementation of the federal target program entitled «Program for promoting an effective and environmentally friendly heat and electricity supply to the central ecological zone of the Baikal Natural Area through the use of renewable sources of energy».

\section{References}

1. IRENA "Renewable Energy Statistics 2020" International Renewable Energy Agency (IRENA), Abu Dhabi, p. 408.

2. T. Kober, H.-W. Schiffer, M. Densing, E. Panos. Global energy perspectives to 2060 - WEC's World Energy Scenarios 2019. Energy Strategy Reviews 31, pp. 100523 (2020).

3. Denis Sidorov, Ildar Muftahov, Nikita Tomin, Dmitriy Karamov, Daniil Panasetsky, Aliona Dreglea, Fang Liu, Aoife Foley. A Dynamic Analysis of Energy Storage with Renewable and Diesel Generation Using Volterra Equations. IEEE Transactions on Industrial Informatics 16 no. 5: 34513459 (2020).

4. Sidorov D., Panasetsky D., Tomin N., Karamov D., Zhukov A., Muftahov I., Dreglea A., Liu F., Li Y. Toward zero-emission hybrid AC/DC power systems with renewable energy sources and storages: A case study from Lake Baikal region. Energies 13 no 5: ID: 1226 (2020).

5. Dufo-López R., Lujano-Rojas J. M., Bernal-Agustín J. L. Comparison of different lead-acid battery lifetime prediction models for use in simulation of stand-alone photovoltaic systems. Applied Energy 115: 242-253 (2014).

6. Karamov D.N., Minarchenko I.M., Kolosnitsyn A.V., Pavlov N.V. Installed capacity optimization of autonomous photovoltaic systems under energy service contracting. Energy Conversion and Management 240: 114256 (2021).

7. Karamov D.N. Formation of initial meteorological arrays with the use of long-term series FM 12 Synop and METAR in systems energy studies. Bulletin of the Tomsk Polytechnic University. Geo Assets Engineering 329 no. 1: 69-88 (2018).

8. Karamov D.N. Mathematical modeling of solar irradiance based on open access long-term meteorological observation data. Bulletin of the Tomsk Polytechnic University. Geo Assets Engineering 328 no. 6: 28-37 (2017).

9. Karamov D.N., Naumov I.V., Ivanov D.A., Podyachikh S. V. Modelling of diesel generator operating modes on the basis of the engine speed characteristic in autonomous photovoltaic systems CEUR Workshop Proceedings 2638: 12 (2020).

10. Karamov D.N. Methodology for calculating the lifetime of storage batteries in autonomous energy systems with renewable power generation. Energy Reports 6, Suppl. 9: pp. 15-24 (2020). 